\title{
Role and importance of formation of legal competence of civil engineering students
}

\author{
Olga Pavlycheva ${ }^{1, *}$ \\ ${ }^{1}$ Moscow State University of Civil Engineering, Yaroslavskoye sh., 26, Moscow, 129337, Russia
}

\begin{abstract}
In modern society the understanding is growing that eradication of legal illiteracy of the population is not only a condition of the existence of a democratic civil society in the modern state, but also a mandatory requirement for the vocational training of a competent specialist, including construction industry. The acquisition of legal knowledge in professional sphere predominantly is carried out in the university through formation of legal competence. Thus, the role and importance of legal competence formation is determined with account of state educational policy. It is pointed out that legal competence is present in all subgroups of general competence. The article considers the problem of formation of future engineer's legal competence as well as suggests some ways to solve it.
\end{abstract}

\section{Introduction}

The change of the traditional education paradigm to the learner-centered one and transition of Russian education to testate educational standards require the higher school to improve the vocational training of a student to become a competent specialist not only in his professional sphere but also in the legal one[1,2].

The concept of modernization of the Russian education determines the educational system not only to train people able to live in a civil society and constitutional state, as well as able to create them. Nowadays, the system forms a new type of person - "law-conscious citizen", who is characterized by a high level of legal competence and legal culture.

According to studies, the urgency of this problem consists in an increase of the legal culture level of non-legal specialists, including the civil engineering sector. There is a number of contradictions, which impede solution of the problem of the legal competence formation of a student during his study at university. Thus, I.Y. Saraeva[3] identifies in his thesis the following challenges:

- between contemporary society's requirements of a high competence level of a specialist and traditional approaches with a good knowledge in the legal regulation;

- between attempts to introduce a block of legal disciplines into the system of higher education and a real level of legal knowledge;

- between the need for future specialist to be up to speed on the legislation, its implementation mechanisms and ways to protect their inalienable rights.

*Corresponding author: olganik78@mail.ru 
However, despite of the problems and difficulties of the educational process, the primary objective of legal education of future specialists at civil engineering university should be determined. In our opinion, it can be represented in the form of 3 components:

- acquire a certain amount of legal knowledge;

- form an active position in the legal sphere, economy and everyday life;

- acquire sufficient skills to apply the legal knowledge in everyday situations as well assign professional ones.

\section{Materials and Methods}

Federal Law "On Education in Russian Federation" dated 29.12.2012 [4] in article 3 refers to the basic principles of the state policy and legal regulation in the field of education:

- Recognition of the priority of education;

- Ensuring the right of every person to education, the inadmissibility of discrimination in education;

- Humanistic nature of education, the priority of human life and health, rights and freedoms, free development of personality, upbringing of mutual respect, hard work, citizenship, patriotism, responsibility, legal culture, respect for nature and the environment, environmental management.

In this regard, high requirements in the context of professional culture and education are indented to a graduate of the modern university of civil engineering.

As it is noted in the "Concept of long-term Russia's social and economic development for the period till 2020", the main purpose of vocational training is to train skilled employees of appropriate level and profile, competitive at labor market, competent, responsible, fluent in their profession and confident in related fields, ready for professional development as well as social and professional mobility [5].

Achieving these goals and objectives in terms of higher education is possible only through formation of the legal competence of students that allows learners to get an idea of the rights and freedoms, to expand the possibilities to develop spiritual and material needs of the individual, to generate the readiness to become future expert able to make decisions and self-responsible in the political, economic and cultural life of the country.

On this basis, according to O.R. Chudinov [6], the interests of an individual to develop one's competence, creativity and general culture can be considered as a priority for higher education. This makes it possible to begin pushing into focus the learner (student) as an active subject who acquires education in the form of "personal knowledge". At the same time it does not eliminate the problem of formation of professional qualities, what is usually called professional competence.

Developing the mechanism of legal competence formation during the tertiary education, including civil engineering, choosing the techniques and methods to acquire the legal knowledge and develop abilities and skills to apply them, one can't ignore the specifics of higher school.

Features of the educational process in the higher education system have been shown in O.V.Zandanovathesis research [7]. Higher education level as a part of the social institution of education is represented in the form of specialized organizations with joint activity of people (teachers, students, administrative managers, support staff), specifically organizing the learning process and education of young professionals in order to transfer their professional knowledge, skills and socially significant values of science, culture and morality.

University is significantly different from other professional education institutions. It has its own specifics of organization of educational process, system of indicators of education quality, factors affecting them and the means of managing these factors. In addition, it 
entails major changes in the organization and the nature of the training activities and in the general way of life of young people. Changes are related to the increase of the study load, mastering of the professional general training, study of the disciplines of the specialization, mandatory practical orientation of the educational process, focus on the creative development of students, increasing importance of independent work as a form of their individual training activities[8].

The main goal of the university as an educational institution is a professional education, which full implementation contributes to the personality development of the future specialist [7].

The application of one of the classical methods of legal research made it possible to determine the role and significance of the legal competence of the student in the process of studying at the university. This is a method of comparative legal research, which made it possible to conduct a legal analysis of normative legal acts and scientific literature on the subject of research to identify the most urgent problems and find possible solutions for them.

\section{Results}

Currently,there are a number of problems in training of specialists, including the level of legal training of future civil engineers: they do not have any legal knowledge required to work orare unable to apply their knowledge, showing carelessness and legal illiteracy. What is the reason?

The reason is seen in the following: understated requirements of legal competence. This is expressed by

1. distribution of study hours for legal discipline in not sufficient amount to form the competence;

2. the use of the offset system in the knowledge assessment, which does not allow to adequately assess the level of the competence development, on the one hand, and the inability to encourage students to study discipline more closely, on the other;

3. the inclusion in the educational process of the so-called "general educational disciplines" that unite the law in its structure with other humanitarian disciplines: sociology, political science, psychology [9]. In this case, the amount of time to study every included disciplines irreversibly reduced, which affects the quality of the competence formation.

In our opinion, this approach in teachings fundamentally wrong, since not only it does not allow students to form the legal competence in full, but also distorts the representation of students about the independence and integrity of each of these branches of science.

Let us consider the definition of "legal competence" in a non-legal university.

Given the lack of a common understanding, we give a few definitions here.

M.E. Polyakova in relation to students of technical specialty said that "the legal professional competence is a holistic education of his personality, reflecting the readiness to solve problems that require legal knowledge, as well as to their use in professional activity" [10].

According to D. Filankovskiy, the legal competence of non-legal professional profile is a set of qualities that reflect the level of qualifications, level of legal knowledge and skills, the willingness and ability to implement it inspecialist'slegal activities. [11].

O.R. Chudinov points out that the legal competence of a technical university graduate has a cumulative result of education and training, which is a comprehensive description of the mastered them legal knowledge and law enforcement skills, formed of justice and readiness to participate in the legal reality both at professional and civil level, the ability to interact with law enforcement agencies of the state [6]. 
The peculiarity of legal competence is its pervasive nature; it is present in all subgroups of competence. One can't but agree with O.R. Chudinov, that the legal components are present in the core of basic or common cultural competence and professional competence. Within the framework the legal component of professional competence is expressed in the ability to use the obligatory legal documents, to have an understanding of the legal status of the subjects of legal relations in the sphere of professional activity; to know the laws and other normative documents regulating relations in the course of employment; to possess knowledge, skills and abilities in the field of general and sectoral law; to be able to protect their rights in accordance with labor legislation [6].

The projects of new educational standards confirm the statement above.

Therefore, Federal educational standard's projects in the directions of undergraduate, in particular in areas of training 07.03.01 "Architecture" and 03.07.04 "Urban planning" include the need to establish the legal competence, identifying them as:

- UK-2 (the ability to determine the range of tasks within the framework of the goal and choose the best ways to solve them on the basis of existing law, existing resources and restrictions);

- OPK-3 (the ability to participate in the comprehensive design, based on a systematic approach, based on the existing law, the financial resources, analysis of the situation in the social, functional, ecological, technological, engineering, historic, economic and aesthetic aspects).

- Federal educational standard's projects at the level of specialty, for example, in the specialty 08.05.01 "Construction of unique buildings and facilities" include the formation of the following competencies related to the right:

- OPK-3 (the ability to make decisions in their professional activity, using the theoretical framework, the regulatory framework, practical experience in capital construction, as well as knowledge about the present level of its development),

- OPK-4 (the ability to develop project and administrative documentation, to participate in the development of regulatory documents in the field of capital construction),

- OPK-6 (the ability to implement and manage development projects of buildings and structures, taking into account economic, environmental and social requirements and security requirements, the ability to execute a feasibility study of design solutions of buildings and constructions, to carry out the technical appraisal of projects and supervision over their observance),

- OPK-10 (the ability to implement and organize technical operation, maintenance and repair of buildings and constructions, monitoring, control and supervision in the sphere of safety of buildings and structures).

\section{Discussion}

Thus, the successful formation of skills within the legal competence has a significant impact on the qualifications of graduates. The employer often notes the lack of sufficient qualification of young professionals, especially ignorance of the regulatory documents governing professional activity, and the inability to work with them.

This problem is presented in two aspects.

1. In the educational process higher schools of non-legal profile provide not enough training time to develop legal knowledge and skills within the framework to form the common and professional competences. This adversely affects the quality of training.

The problem can be solved by increasing the study hours for the discipline and, above all, for practical training, as the proposed structure of the courses requires the development of students' skills in law enforcement, which can be achieved only through practical training. The same is with the modern educational standard. Such a situation also occurs 
with the curricula of technical universities, including the civil engineering, by reducing the hours of humanities in general and the "Law" in particular. Teachers are under acute time pressure. [12].

In the educational process it should also be given enough time to work with the laws and regulations in the professional sphere. It will make the process of the professional competence formation of students more efficient.

2. Law teachers, having received a good basic legal training, may not always understand the nuances of legal regulation in future activities of graduates.

Resolving this issue is seen in the organization of retraining and advanced training of teachers of legal disciplines, covering those fields of law, which are necessary for the training of the expert in a particular field of his future activities. This, of course, does not exclude and does not replace the need for professional development in the field of education techniques [13]). Certain in-depth study and a systematic updating of their knowledge by the teachers will enable the learning process more complete and efficient.

\section{Conclusions}

Thus, the formation of legal competence in the process of training students of non-legal professions should be given much more attention than it is currently occurring. The great role of knowledge in the field of law is emphasized in legislation and scientific literature. Specialists who graduated from higher education institutions and work in the specialty should be paid attention to this. One of the ways out of current situation is seen to increase the number of academic hours of legal disciplines and the number of hours for the development of skills, to accumulate knowledge in the field of legal support for professional activities.

\section{References}

1. N.G.Miloradova, A.D.Ishkov, Procedia Engineering117, 246-251 (2015)

2. M.G. Leontev, Procedia - Social and Behavioral Sciences142, 695-701 (2014)

3. I.Y. Saraeva, OrenburgState University1, 21 (2005)

4. Russian Federal Law N 273-FZ

5. The concept of Russian Federation long-term socio-economic development for the period until 2020 (2008)

6. O.R. Chudinov, Herald PNIPU6, 53 (2012)

7. O.V.Zandanova,Formation of legal consciousness of students of non-legal disciplines in the educational process of high school(Sciences, Ulan-Ude, 2010)

8. A.D.Ishkov, N.G.Miloradova, A.Yu. Chernyshev, Procedia - Social and Behavioral Sciences171, 765-770 (2015)

9. E.A. Shnyrenkov, E.V. Romanova, Procedia Engineering 117, 336-341 (2015)

10. M.E. Polyakov,Formation of legal competence of students of a technical college(Mosk. mountains. ped. Univ.,Moscow, 2007)

11. D.V. Filankovskiy, Scientific problems of humanitarian studies scholar 6, 32 (2011)

12. V.V. Nikulin, Special Edition 38, 91 (2012)

13. E.A.Shnyrenkov, I.P. Pryadko, Procedia Engineering117,325-330(2015) 